Review

\title{
Neutropenia and Large Granular Lymphocyte Leukemia: From Pathogenesis to Therapeutic Options
}

\author{
Giulia Calabretto ${ }^{1,2}\left(\mathbb{D}\right.$, Antonella Teramo ${ }^{1,2}$, Gregorio Barilà ${ }^{1,2}\left(\mathbb{0}\right.$, Cristina Vicenzetto ${ }^{1,2}$, \\ Vanessa Rebecca Gasparini ${ }^{1,2}{ }^{-}$, Gianpietro Semenzato ${ }^{1,2, *}$ and Renato Zambello ${ }^{1,2, *}$ \\ 1 Department of Medicine, Padua University School of Medicine, 35129 Padua, Italy; \\ giulia.calabretto@gmail.com (G.C.); antonella.teramo@unipd.it (A.T.); gregorio.barila@gmail.com (G.B.); \\ cristina.vicenzetto@gmail.com (C.V.); vanessarebecca.gasparini@gmail.com (V.R.G.) \\ 2 Veneto Institute of Molecular Medicine, 35129 Padova, Italy \\ * Correspondence: g.semenzato@unipd.it (G.S.); r.zambello@unipd.it (R.Z.)
}

Citation: Calabretto, G.; Teramo, A.; Barilà, G.; Vicenzetto, C.; Gasparini, V.R.; Semenzato, G.; Zambello, R. Neutropenia and Large Granular Lymphocyte Leukemia: From Pathogenesis to Therapeutic Options. Cells 2021, 10, 2800. https://doi.org/ 10.3390/cells10102800

Academic Editor: Fabrizio Mattei

Received: 20 August 2021

Accepted: 13 October 2021

Published: 19 October 2021

Publisher's Note: MDPI stays neutral with regard to jurisdictional claims in published maps and institutional affiliations.

Copyright: (c) 2021 by the authors. Licensee MDPI, Basel, Switzerland. This article is an open access article distributed under the terms and conditions of the Creative Commons Attribution (CC BY) license (https:/ / creativecommons.org/licenses/by/ $4.0 /)$.

\begin{abstract}
Large granular lymphocyte leukemia (LGLL) is a rare lymphoproliferative disorder characterized by the clonal expansion of cytotoxic T-LGL or NK cells. Chronic isolated neutropenia represents the clinical hallmark of the disease, being present in up to $80 \%$ of cases. New advances were made in the biological characterization of neutropenia in these patients, in particular STAT3 mutations and a discrete immunophenotype are now recognized as relevant features. Nevertheless, the etiology of LGLL-related neutropenia is not completely elucidated and several mechanisms, including humoral abnormalities, bone marrow infiltration/substitution and cell-mediated cytotoxicity might cooperate to its pathogenesis. As a consequence of the multifactorial nature of LGLL-related neutropenia, a targeted therapeutic approach for neutropenic patients has not been developed yet; moreover, specific guidelines based on prospective trials are still lacking, thus making the treatment of this disorder a complex and challenging task. Immunosuppressive therapy represents the current, although poorly effective, therapeutic strategy. The recent identification of a STAT3-mediated miR-146b down-regulation in neutropenic T-LGLL patients emphasized the pathogenetic role of STAT3 activation in neutropenia development. Accordingly, JAK/STAT3 axis inhibition and miR146b restoration might represent tempting strategies and should be prospectively evaluated for the treatment of neutropenic LGLL patients.
\end{abstract}

Keywords: neutropenia; large granular lymphocytes; STAT3; immunosuppressive therapy

\section{Introduction}

Large granular lymphocyte leukemia (LGLL) is a rare lymphoproliferative disorder characterized by the clonal expansion of cytotoxic T-large granular lymphocytes (T-LGL) or natural killer (NK) cells [1]. According to the 2016 revision of the World Health Organization's classification of lymphoid neoplasms [2], LGLL is included among T/NK cell neoplasms, with a reported incidence of $0.2-0.72$ cases per 1 million individuals per year, based on the American and Dutch registries, respectively [3,4].

T-LGL leukemia (T-LGLL) and the chronic lymphoproliferative disorder of NK cells (CLPD-NK) represent the most common subsets of the disease, accounting for $\sim 85 \%$ and $\sim 10 \%$ of cases, respectively [5]. Both disorders share common molecular alterations, such as the activation of several pro-survival signaling pathways and somatic mutations in the signal transducer and activator of transcription (STAT) genes [6,7].

Although heterogeneous, the clinical course of the disease is typically characterized by neutropenia, which turns out to be the main clinical feature, being present in up to $80 \%$ of patients along the disease course, with severe neutropenia characterizing $17-24 \%$ of cases [1,7]. Other relevant manifestations include anemia and thrombocytopenia, reported in $13-49 \%$ and $6-30 \%$ of cases, respectively [1,8-11]. 
Being that neutropenia is the clinical hallmark of LGLL, great efforts have been devoted to understanding its pathogenesis, in contrast with anemia or other clinical manifestations, which still remain less investigated.

Herein, we will discuss the putative pathogenetic hypotheses and mechanisms accounting for neutropenia development, particularly the recent identification of a microRNA(miR)$146 \mathrm{~b}$ defective expression in leukemic T-LGL [12]. Moreover, we will focus on both current therapies and novel promising strategies for the treatment of neutropenic LGLL patients.

\section{Immunological Deregulations in LGLL Patients}

LGLL could be ideally placed at the intersection between a clonal lymphoproliferative disorder, autoimmunity and chronic inflammation [13]. The pathogenesis of LGLL is recognized as a multi-step process, with a chronic antigenic pressure (likely a self or viral peptide) being the triggering event for LGL activation and expansion [7]. A close topographic distribution between leukemic and dendritic cells (DC) was also described in bone marrow (BM) of patients, thus suggesting a putative role of DC in antigen presentation [14]. In turn, a strong pro-inflammatory environment plays a crucial role in LGLL pathogenesis: several cytokines and chemokines (e.g., IL-2 [15], IL-6 [16], IL-15 [17,18], IL18, RANTES [19], PDGF [20]) are increased in sera of patients as compared to the controls, promoting LGL survival and proliferation. Of note, IL-6 was shown to be highly expressed by the non-leukemic fraction of peripheral blood mononuclear cells, thus supporting a role of other immune cell deregulations in the pathogenesis of the disease [16].

Consistently, a wide spectrum of immunological alterations (e.g., rheumatoid factor, anti-nuclear antibodies, anti-neutrophil antibodies or direct coombs) are described in LGLL patients, emphasizing the immune background of the disease [21]. A peculiar association of LGLL with autoimmune disorders is also reported, notably rheumatoid arthritis (RA), occurring in 11-36\% of cases [22]. Other hematological diseases and BM failure syndromes, such as myelodysplastic syndrome (MDS), paroxysmal nocturnal hemoglobinuria (PNH), aplastic anemia (AA) and pure red cell aplasia (PRCA) frequently co-occur with LGLL (Figure 1), hinting at a widespread dysfunction of the immune system in these patients [21].

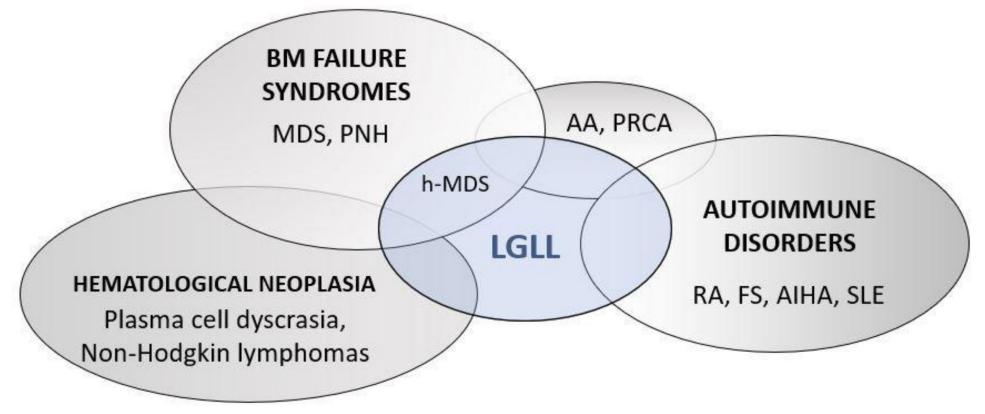

Figure 1. Immuno-pathogenetic background of LGLL. The Euler-Venn diagrams show the intersection between LGLL, BM failure syndromes, hematological and autoimmune diseases, emphasizing the immune and pro-inflammatory background of LGLL. AA, aplastic anemia; AIHA, Auto immune hemolytic anemia; FS, felty syndrome; h-MDS, hypocellular myelodysplastic syndrome; MDS, myelodysplastic syndrome; PNH, paroxysmal nocturnal hemoglobinuria; PRCA, pure red cell aplasia; RA, rheumatoid arthritis; SLE, systemic lupus erythematosus.

\section{Neutrophils Lifespan and Neutropenia}

Neutrophils (or polymorphonuclear leukocytes, PMN) are crucial effectors of the immune system that can be rapidly recruited to the infection sites, providing a first line of defense against pathogens. Neutrophils are produced in the BM at a rate of $10^{11}$ cells/day and, in physiological conditions, they are the most represented human white blood cells. This large-scale production is counterbalanced by their short life span in the bloodstream (less than $24 \mathrm{~h}$ ) $[23,24]$. 
PMN clearance can be achieved through different mechanisms, including apoptosis and non-conventional pathways, i.e., phagocytosis-induced cell death (PICD) and autophagy. Neutrophil apoptosis can be promoted by extracellular signals (extrinsic pathways) or mitochondrial-related alterations (intrinsic pathways). In detail, extrinsic apoptotic pathways are triggered by the engagement of death receptors belonging to the tumor necrosis factor (TNF) superfamily by their respective ligands, i.e., Fas ligand (FasL), TNF- $\alpha$ and TNF-related apoptosis inducing ligand (TRAIL) $[25,26]$.

In order to maintain the immune-homeostasis and to avoid the development of infectious or inflammatory diseases, the production and turnover of PMN must be finely regulated. The normal value of the absolute neutrophil count (ANC) ranges between 1.5 to $7 \times 10^{9} / \mathrm{L}$, with different thresholds based on age, sex and ethnicity. Neutropenia, commonly defined by an ANC $<1.5 \times 10^{9} / \mathrm{L}$, is classified as mild (ANC $>1 \times 10^{9} / \mathrm{L}$ ), moderate (ANC $>0.5 \times 10^{9} / \mathrm{L}$ and $<1 \times 10^{9} / \mathrm{L}$ ), or severe (ANC $<0.5 \times 10^{9} / \mathrm{L}$ ); moreover, it can be transient or chronic, i.e., characterized by a reduction of the ANC for at least three months [27]. Chronic neutropenias can be ascribable to a congenital defect, as in the case of cyclic neutropenia, an autosomal dominant disease characterized by regular fluctuations of the neutrophil count. Differently, they can be consequent to an acquired issue and are further distinguished in primary (unknown etiology), secondary (related to an underlying disease) and drug-induced (occurring as a consequence of drug administrations). In detail, secondary acquired neutropenias can be associated with hematological diseases, such as in LGLL patients, as well as with autoimmune diseases, solid tumors or primary immunodeficiency syndromes [28,29].

\section{Pathogenetic Hypotheses of LGLL-Related Neutropenia}

The pathophysiological mechanisms underlying a chronic acquired neutropenia are various, ranging from an impaired granulopoiesis to a shortened survival of myeloid progenitors or mature neutrophils. According to the biological heterogeneity of LGLL, a unique molecular mechanism accounting for the development of neutropenia has not yet been identified, thus its pathogenesis has long been reported as a multifactorial process [29-31]. Three main mechanisms, alone or concurrent, were identified to explain LGLL-related neutropenia and can be classified in humoral abnormalities, BM infiltration/substitution and cell-mediated cytotoxicity (Figure 2).

\subsection{Humoral Mechanisms (Figure 2A)}

A wide spectrum of serological abnormalities is described in LGLL patients, suggesting that inflammatory or autoimmune mechanisms might play a significant role in the clinical manifestations of the disease. In particular, the finding of anti-neutrophils antibodies in sera of neutropenic patients would support an immune-mediated destruction of PMN. However, several studies failed to detect them or restricted this mechanism to a discrete subset of cases [32-38].

Otherwise, high levels of soluble Fas ligand (s-FasL) are found in sera of almost all neutropenic patients, as compared to patients with normal ANC and healthy controls [39-41]. The constitutive expression of FasL represents a peculiar feature of leukemic LGL, differently from normal cytotoxic lymphocytes, in which FasL expression occurs upon activation $[42,43]$. The shedding of membrane-bound FasL by ADAMs (i.e., proteins with a disintegrin and metalloprotease domain) allows the release of a soluble form of FasL (s-FasL); in turn, s-FasL is able to trigger neutrophil apoptosis via the extrinsic pathway. Consistent with a pathogenetic role of s-FasL, sera of LGLL patients were shown to induce in-vitro apoptosis of normal neutrophils; moreover, the clinical resolution of neutropenia in treated patients was associated with a reduction in s-FasL levels, which in most of cases resulted even undetectable [40,44]. PMN were also shown to be more sensitive to Fas-induced apoptosis as compared to other Fas-expressing cells, such as monocytes and eosinophils $[25,45]$, supporting the finding of an isolated cytopenia in LGLL patients. 


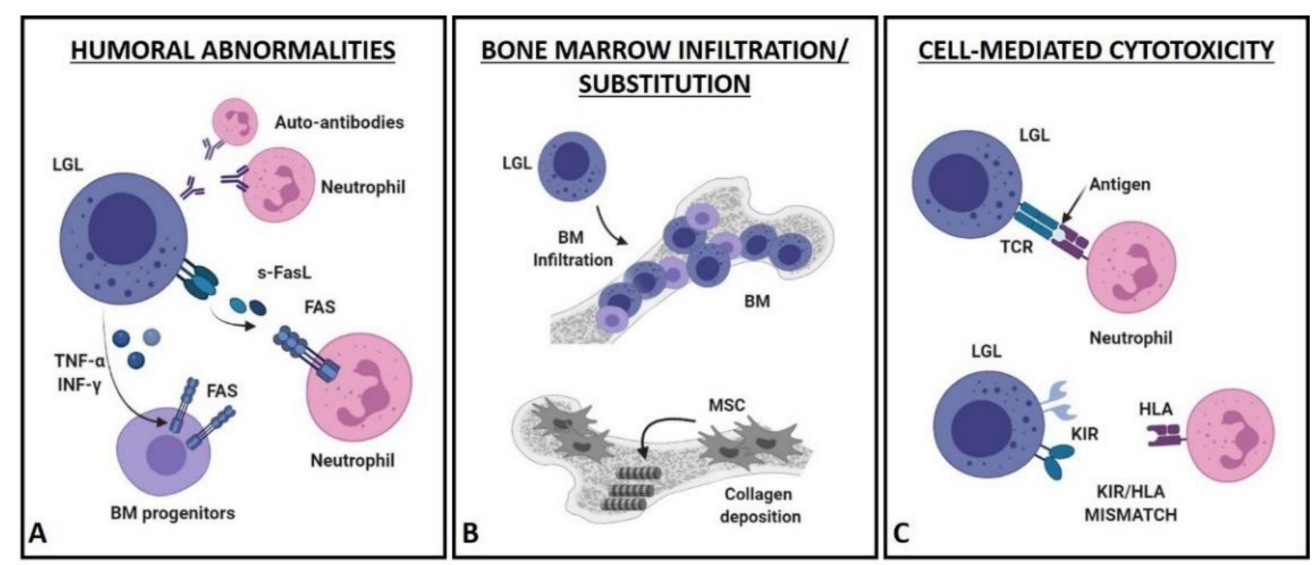

Figure 2. Pathogenetic mechanisms of neutropenia. (A) Humoral abnormalities include antineutrophil antibodies and the release of soluble FasL, TNF- $\alpha$ and IFN- $\gamma$ by leukemic cells. Fas-FasL interaction triggers neutrophils apoptosis. TNF- $\alpha$ and IFN- $\gamma$, instead, are supposed to promote Fas expression on BM myeloid progenitors. (B) BM infiltration by leukemic LGL or BM substitution, due to an excessive collagen deposition by MSC, might lead to an impaired granulopoiesis. (C) The expression of peculiar TCR/KIR on leukemic cells surface might be responsible of a cellmediated cytotoxicity against neutrophils. BM: Bone marrow; HLA: human leukocyte antigens; IFN- $\gamma$ : interferon- $\gamma$; KIR: killer immunoglobulin-like receptors; LGL: large granular lymphocytes; MSC: mesenchymal stromal cells; s-FasL: soluble Fas ligand; TCR: T-cell receptor; TNF- $\alpha$ : tumor necrosis factor $\alpha$.

In physiological conditions, Fas receptor is not expressed by hematopoietic progenitors, suggesting that Fas-mediated apoptosis might be a pathogenetic mechanism restricted to mature neutrophils. However, an upregulation of Fas on CD34+ cells was demonstrated both in vitro, after stimulation with TNF- $\alpha$ and interferon- $\gamma$ (IFN- $\gamma)$, and in vivo in patients with aplastic anemia (AA), which are characterized by an overexpression of these cytokines $[46,47]$. Since leukemic T-LGL are able to spontaneously produce INF- $\gamma$ and to secrete TNF- $\alpha$ upon stimulation, a cytokine-related increase of Fas expression on CD34+ BM precursors is likely to occur in BM of neutropenic LGLL patients, leading to a Fas-mediated apoptosis of myeloid or erythroid progenitors [48-50]. This hypothesis, however, does not explain the higher frequency of LGLL patients with isolated cytopenia as compared to the broad suppression of hematopoietic cells occurring in AA. In addition, the expression of Fas on granulocyte precursors was never addressed, thus the potential involvement of TNF- $\alpha$ and IFN- $\gamma$ still remains to be elucidated.

\subsection{Bone Marrow Infiltration/Substitution (Figure 2B)}

Only few reports have taken into account the peculiar BM appearance of LGLL patients, mostly describing a moderate or marked hypercellularity and an interstitial lymphoid infiltration [51-53], with clusters of at least eight CD8+/TIA1+ cells or six granzyme B+ lymphocytes being a common histopathological finding [54]. A typical feature observed in BM of neutropenic patients is the decrease in granulocyte precursors, combined with a left-shift myeloid maturation (i.e., an increase in immature myeloid precursors in peripheral blood). An impairment of granulopoiesis is unlikely to occur, since T-LGL from patients did not show a suppressive activity towards neutrophil precursors in vitro [55]. Differently, BM invasion by clonal LGL might impair the replicative potential of hematopoietic stem cells and progenitors. To date, this issue still remains controversial, since a correlation between the percentage of BM infiltration and the degree of neutropenia (or anemia) was never demonstrated.

A role in neutropenia development could be ascribed also to reticulin fibrosis, usually increased in BM of LGLL patients, ranging from grade 2 to 3 in $50-60 \%$ of cases. Consistent with this hypothesis, patient-derived mesenchymal stromal cells (MSC) have 
shown an abnormal collagen matrix deposition that might interfere with the proliferation of hematopoietic progenitors or promote their premature mobilization [56]. This evidence, however, would not fully explain the high frequency of isolated neutropenia typically observed in these patients, since this mechanism might also support anemia development.

\subsection{Cell-Mediated Cytotoxic Mechanisms (Figure 2C)}

$\mathrm{T}$ and NK cells are characterized by a remarkable phenotypic heterogeneity, based on the variable expression of antigens and receptors, with many of them being members of the killer immunoglobulin-like receptor (KIR) family. The KIR repertoire is highly heterogeneous in the human population; in contrast, LGLL patients show a restricted pattern of KIR, mainly characterized by their activating isoforms, representing a typical feature of the leukemic clone [57-59]. Of note, the expression of specific KIR represents a relevant immunogenetic factor in various BM failure syndromes, including PHN, AA and PRCA $[60,61]$. NK cell activity, indeed, is regulated by the fine tuning of signals coming from inhibitory and activating KIR with their related ligands (i.e., the human leukocyte antigens-HLA). A bias towards the expression of activating KIR, together with a lack of inhibitory signals, might play a role in LGLL-related neutropenia or anemia [50]. To date, the main relevant finding in LGLL patients is the significant occurrence of KIR3DL2/HLAA3/11 and KIR2DS1/HLA-C2 mismatches, which might result in the activation of a greater cytotoxic response or self-intolerance [60,62].

In addition to the possible KIR expression, T-LGL are also equipped with a T-cell receptor (TCR). A high degree of similarity between multiple immunodominant TCR clonotypes is described in LGLL patients, suggesting a non-random clonal selection [63]. Thus, the TCR specificity of leukemic clone might be involved in neutropenia development by recognizing an unknown antigen on neutrophil surface. This issue, however, is still to be addressed, since no evidence of private clonotypes or TCR-variable $\beta(\mathrm{V} \beta)$ regions, exclusively shared by neutropenic LGLL patients, has been provided so far.

\section{Novel Insights in FasL Regulation: The STAT3/miR-146b/FasL Axis}

The most credited mechanism to explain the development of neutropenia relies on the Fas-mediated apoptosis of mature neutrophils or myeloid progenitors. The Fas/FasL pathway plays a crucial role in the immune homeostasis, being involved in the activationinduced cell death (AICD) mechanism. Briefly, the engagement of Fas by FasL leads to receptor trimerization and to the recruitment of Fas-associated death domain (FADD) to Fas cytosolic portion. The complex Fas-FADD, recognized as death-inducing signaling complex (DISC), triggers the proteolytic cleavage and activation of caspase-3, ultimately leading to cell death. In LGLL, the Fas/FasL axis is known to be deregulated. Despite the abundant and constitutive expression of Fas and FasL on their surface, leukemic LGL are resistant to Fas-mediated apoptosis. This resistance is related to an impaired DISC formation and the presence of elevated levels of a soluble form of Fas (s-Fas) in sera of patients that could compete for FasL binding, acting as a decoy receptor. Loss of function mutations in FAS/FASL genes, instead, have not been identified so far [64].

Recently, a significative correlation between STAT3 activating mutations and neutropenia was recently highlighted. STAT3 variants represent the most distinctive genetic lesions described in leukemic LGL, being present in approximately $40 \%$ of patients $[7,41,65]$. Of note, STAT3 activation was shown to drive FasL expression, further supporting a STAT3 pathogenetic role in neutropenia development [41]. The clinical relevance of STAT3 mutations was also confirmed by their association with a symptomatic and treatment-requiring disease, characterized by a reduced overall survival (OS) of patients [10].

Since FasL is not a direct STAT3 target, a high throughput miRNome analysis was performed to investigate miRNA differentially expressed in patients characterized by neutropenia, as compared to those with normal ANC and healthy controls. Selected miRNAs were analyzed for correlation with STAT3 activation and ANC. Intriguingly, miR-146b resulted to be down-regulated in T-LGL of neutropenic patients, due to a hypermethylation 
of its promoter. Of note, a direct role of STAT3 activation was suggested in this epigenetic alteration, by promoting the DNA methyltransferase 1 (DNMT1) expression [12].

The defective expression of miR-146b in leukemic LGL allows an increased translation of human antigen R (HuR), a RNA-binding protein and an essential FasL mRNA stabilizer. HuR-mediated FasL-mRNA stabilization leads to an increase of FasL expression, resulting in higher levels of s-FasL in sera of neutropenic patients [12] (Figure 3).
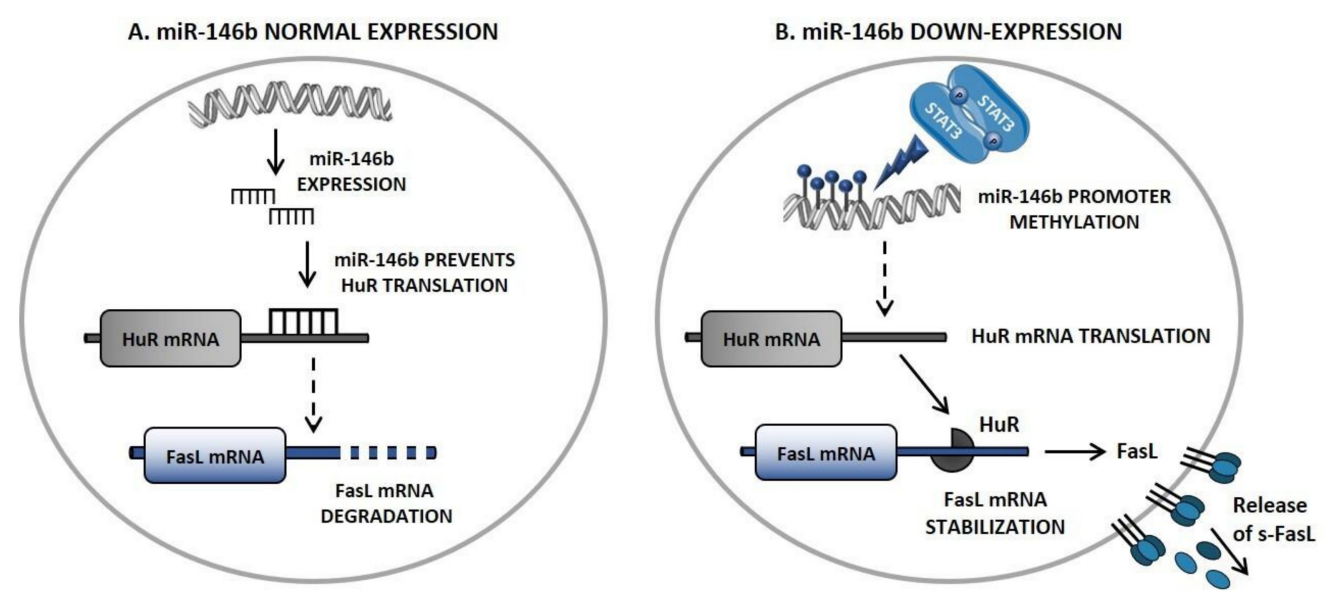

Figure 3. miR-146b/Fas ligand axis. (A) miR-146b normal expression prevents HuR translation, leading to FasL mRNA degradation. (B) STAT3-mediated miR-146b defective expression allows HuR mRNA translation, leading to increased FasL expression by leukemic T-LGL. FasL, Fas ligand; HuR: human antigen R; s-FasL: soluble Fas ligand; miR-146b, micro-RNA 146b; mRNA, messenger RNA; STAT3: signal transducer and activator of transcription 3.

These novel data, emphasizing the role of a STAT3/miR-146b/FasL axis, elucidated the molecular mechanism accounting for the increased s-FasL expression and, for the first time, showed the involvement of an miRNA in the pathogenesis of LGLL-associated neutropenia. Other miRNAs, i.e., miR-223 [66] and miR-29b [18], are reported to be deregulated in T-LGLL patients, suggesting that transcriptional regulators (including long non-coding and circular RNAs) might play a relevant role in the pathogenetic mechanisms of the disease.

\section{The Prognostic Value of Immunophenotype to Identify Neutropenic LGLL Patients}

Leukemic T-LGL typically shows a post-thymic effector-memory phenotype: TCR+, CD3+, CD4-, CD5 ${ }^{\text {dim }}$, CD8+, CD27-, CD28-, CD45RA+, CD45RO-, CD57+, CD62L-, CCR7-, CD122+. Beyond the most common CD4-/CD8+ T-LGL proliferation (referred to as CD8+ T-LGLL), a CD4+/CD8 ${ }^{-/ \text {dim }}$ variant (referred to as CD4+ T-LGLL) is described in approximately $30 \%$ of cases [10]. Moreover, according to the positive or negative expression of three NK cell markers, i.e., CD16, CD56 and CD57, several immunophenotypic combinations were demonstrated in both CD8+ and CD4+ T-LGLL subsets [41].

Notably, a strong correlation between the immunophenotype of the leukemic clone and neutropenia was highlighted. Neutropenic T-LGLL patients are generally included in the CD8+ T-LGLL subset and identified by a peculiar combination of LGL markers, i.e., CD16+/CD56-. On the contrary, neutropenia is rarely observed in the other immunophenotypic subgroups (Table 1). Consistently with this observation, FasL expression was demonstrated to be higher in CD8+/CD16+/CD56- T-LGLL patients, as compared with other immunophenotypic subgroups [41]. 
Table 1. Immunophenotypic signature of neutropenic LGLL patients.

\begin{tabular}{cccccccc}
\hline & CD3 & CD8 & CD4 & CD16 & CD56 & CD57 & Neutropenia \\
\hline & + & + & - & + & - & \pm & Frequent \\
\cline { 2 - 7 } & + & + & - & - & - & + & Rare \\
\cline { 2 - 7 } T-LGLL & + & + & - & - & + & + & Rare \\
\cline { 2 - 7 } & + & + & - & + & + & + & Rare \\
\cline { 2 - 7 } & + & + & - & - & + & - & Rare \\
\hline \multirow{2}{*}{ CLPD- } & - & \pm & - & Bright & $-/$ Dim & - & Frequent \\
\cline { 2 - 7 } NK & - & \pm & - & Bright & $-/ D i m$ & + & Rare \\
\cline { 2 - 7 } & - & \pm & - & Dim & Dim & \pm & Rare \\
\hline
\end{tabular}

Note: CD: Cluster of differentiation; CLPD-NK: chronic lymphoproliferative disorder of NK cells; T-LGLL: T-large granular lymphocyte leukemia.

NK cells exhibit a TCR-, CD2+, sCD3-, CD3e+, CD4-, CD8, \pm CD16+, CD56+ phenotype; moreover, two main subsets can be distinguished according to CD16 and CD56

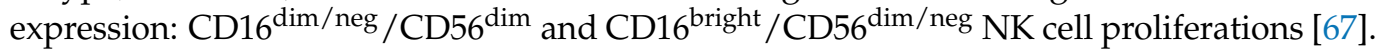
Neutropenic CLPD-NK patients are typically included in the CD16 $6^{\text {bright }} /$ CD56 ${ }^{\mathrm{dim} / \mathrm{neg}} \mathrm{sub}-$ group and characterized by the lack of expression of CD57 [68] (Table 1).

This evidence supports the added value of immunophenotypic analysis to provide relevant prognostic information. Although with some exceptions, STAT3 mutations and/or a discrete phenotype might be useful predictors to early identify and manage this high-risk category of patients.

\section{Differential Diagnosis of LGLL-Related Neutropenia}

Neutropenic LGLL patients are typically characterized by recurrent oral ulcerations and infections, usually bacterial, involving skin, oropharynx, lung and perirectal area. Severe septic complications may also occur and represent the primary cause of related death in approximately $5-10 \%$ of cases. Acute viral and fungal infections are less common, while opportunistic infections are rarely observed [13,22,69].

Although the diagnostic work-up of neutropenia is beyond the aim of this review, there are some specific conditions that need to be considered in the differential diagnosis of LGLL-related neutropenia. LGLL diagnosis requires evidence of a chronic-expanded clonal LGL population. Peripheral blood (PB) immunophenotypic analysis, by flow cytometry, is mandatory to define LGL expansion. A threshold of at least $0.5 \times 10^{9} \mathrm{LGL} / \mathrm{L}$ is now currently recognized; exceptionally, a LGL count lower than $0.5 \times 10^{9} / \mathrm{L}$, associated with a proper clinical context, can also be accepted $[7,22]$. Clonality can be assessed by TCR- $\gamma$ gene rearrangement and TCR-V $\beta$ repertoire analyses in T-LGL proliferations. As a consequence of the lack of TCR in NK cells, a restricted pattern of KIR expression is commonly used as a surrogate of clonality for NK cell expansions [7].

The demonstration of clonality allows to distinguish reactive from truly leukemic proliferations (Figure 4). In this regard, clonality assessment might be useful in the differential diagnosis with felty syndrome (FS), an autoimmune condition characterized by the triad of RA, neutropenia and splenomegaly. A significant number of LGLL patients, indeed, display concomitant RA. Distinguishing concomitant LGLL/RA from FS is quite challenging, since predilection of HLA-DR4 and somatic STAT3 mutations can be detected in both conditions, supporting the hypothesis that these diseases share common pathogenetic mechanisms $[30,70]$. 


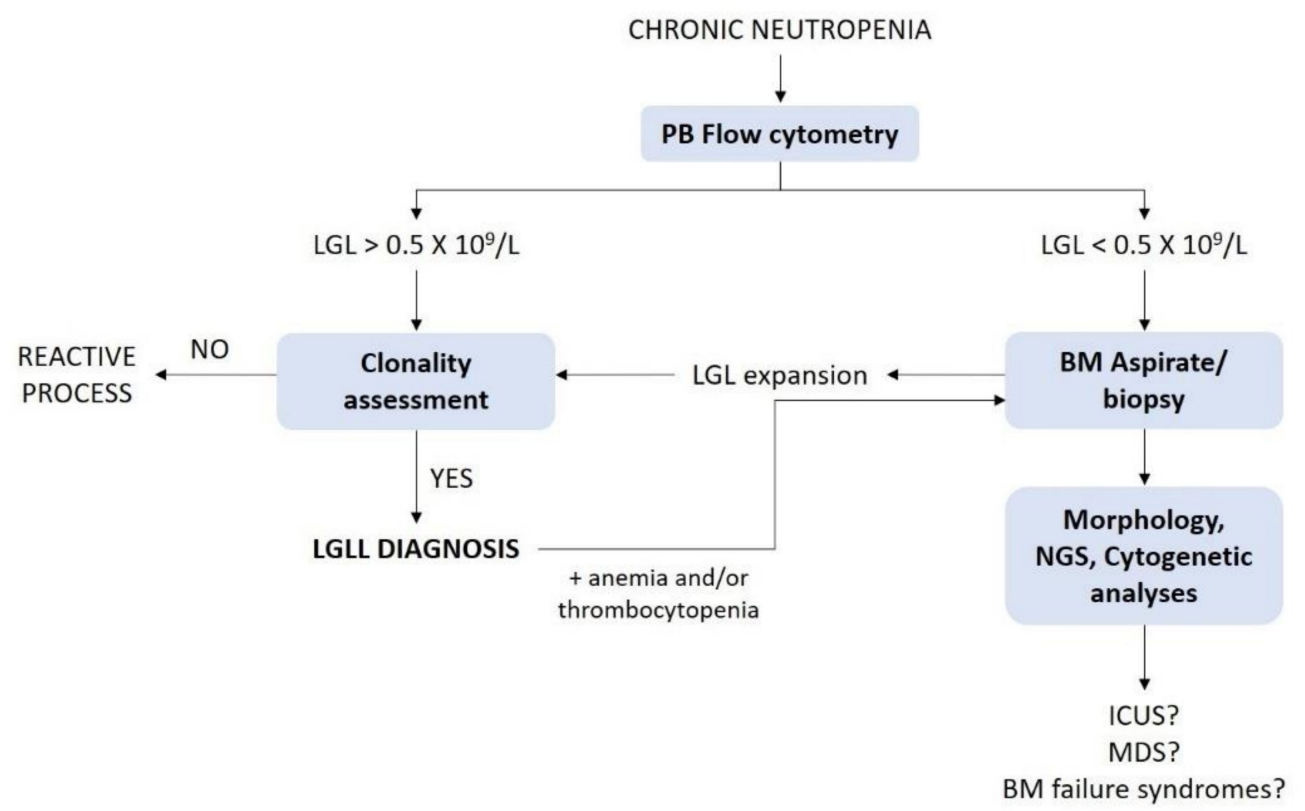

Figure 4. Diagnostic work-flow of LGLL-related neutropenia. BM: Bone marrow; ICUS: idiopathic cytopenia of undetermined significance; LGL: large granular lymphocytes; LGLL: large granular lymphocytes leukemia; MDS: myelodysplastic syndromes; NGS: next generation sequencing; PB: peripheral blood.

Since the diagnosis of LGLL is usually established by PB analysis, BM aspirate and/or biopsy are not routinely performed as part of the initial evaluation; BM investigation is rather recommended when the diagnosis is not straightforward, since it might help to elucidate the etiology of unexplained cytopenias [7] (Figure 4). In this regard, LGLL is frequently associated with BM failure syndrome, particularly MDS, according to a recent series showing LGL clonal expansion in approximately one-third of MDS cases [70].

Differential diagnosis is central to correctly address the therapeutic decision; in particular, alkylating agents should be avoided in the setting of concomitant myeloid neoplasms, due to the increased risk of progression to acute myeloid leukemia. In addition to neutropenia, patients with concomitant LGLL and MDS generally display anemia and/or thrombocytopenia, typical MDS-related features, such as myeloid dysplasia, cytogenetic abnormalities, increase in blasts count and the presence of clonal myeloid mutations (e.g., TET2, DNMT3A, SF3B1, ASXL1) [71,72]. Somatic mutations in STAT3, instead, can be detected in both concomitant LGLL/MDS and LGLL/AA patients, although with lower frequency as compared to LGLL cases [72,73].

\section{Treatment Indications for Neutropenic LGLL Patients}

LGLL patients are characterized by a heterogenous clinical course. They may remain asymptomatic for a long time, but roughly $2 / 3$ of them develop symptoms during the natural history of the disease, with $30-70 \%$ of cases requiring therapy $[50,74,75]$. According to current concepts, treatment of LGLL patients is required in the presence of symptomatic or severe $\left(\mathrm{ANC}<0.5 \times 10^{9} / \mathrm{L}\right)$ neutropenia, symptomatic or transfusion-dependent anemia and associated autoimmune conditions [76]. In our Hematology Unit, at Padua University Hospital (Italy), asymptomatic patients, even with severe neutropenia, are not systematically treated. Recent data showed a comparable OS between treated-patients with symptomatic neutropenia and untreated-patients with severe but asymptomatic neutropenia, thus supporting our clinical approach [10].

Current conventional therapeutic strategy for LGLL patients relies on immunosuppressive therapy (IST), based on retrospective data. A targeted treatment for neutropenic patients does not exist yet and patients presenting with neutropenia share the same therapeutic options of those characterized by other clinical manifestations. Moreover, the 
overall response rate (ORR) and long-lasting responses are unsatisfactory, with a high number of relapsed/refractory $(R / R)$ patients, highlighting the need for novel and effective therapeutic approaches [22].

In the following paragraphs, we will discuss the available therapeutic options, as well as emerging and promising therapies for the treatment of LGLL patients, with particular attention to those presenting with neutropenia (Figure 5).

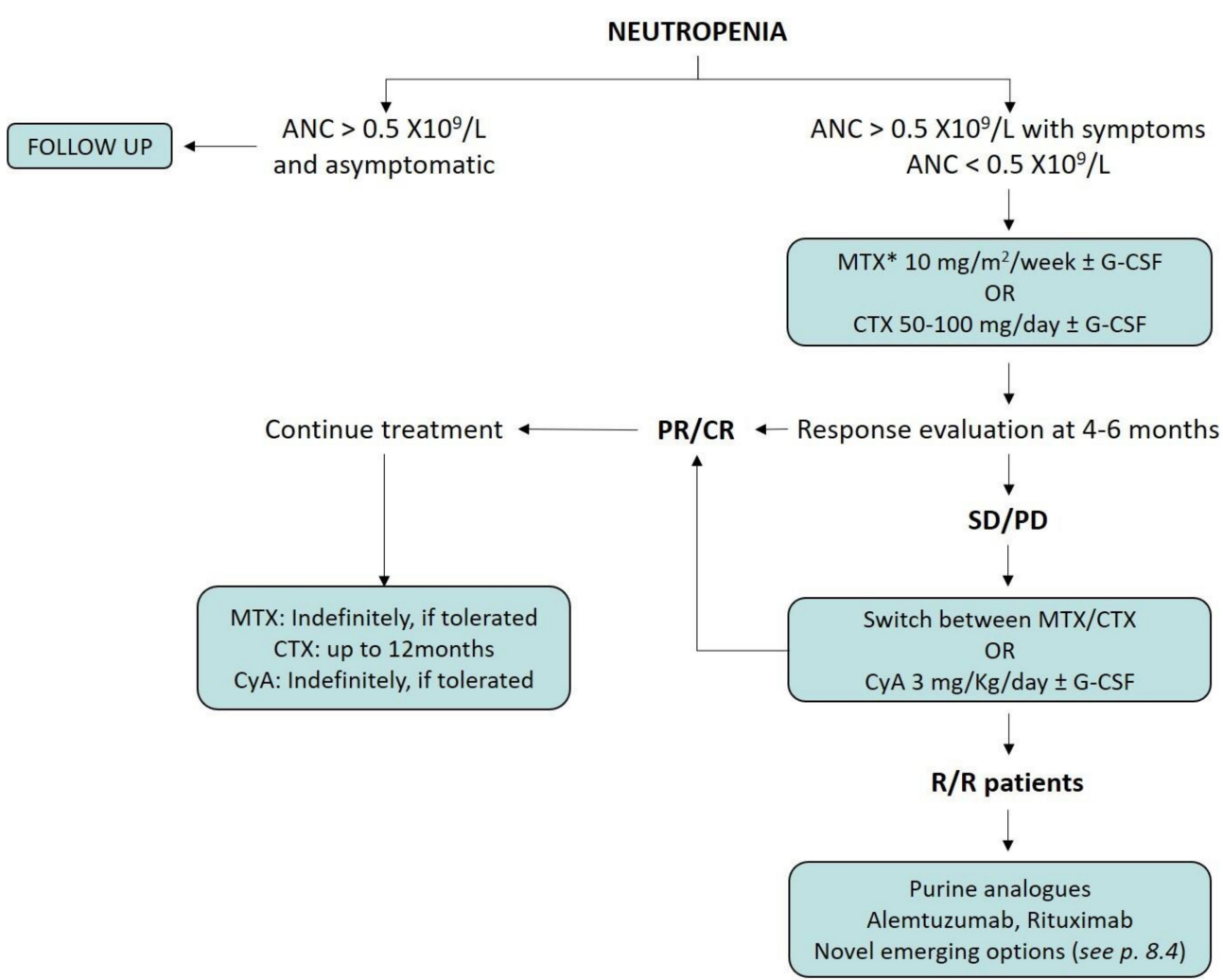

Figure 5. Treatment algorithm for neutropenic LGLL patients. ${ }^{*} \mathrm{MTX}$ to be preferred in STAT3 Y640F patients; ANC: absolute neutrophil count; CR: complete response; CyA: Cyclosporine A; CTX: cyclophosphamide; G-CSF: granulocyte-colony stimulating factor; MTX: methotrexate; PD: progressive disease; PR: partial response; R/R: relapsed/refractory; SD: stable disease.

\subsection{Immunosuppressive Therapy}

First-line therapy usually relies on single-agent methotrexate (MTX, $10 \mathrm{mg} / \mathrm{m}^{2}$ per week) or cyclophosphamide (CTX, 50-100 mg per day), typically combined with steroids administration (e.g., prednisone $1 \mathrm{mg} / \mathrm{kg}$ orally daily, 30 days then gradually tapered [74]). A switch between MTX and CTX is recommended as second-line, restricting cyclosporine A (CyA, $3 \mathrm{mg} / \mathrm{Kg}$ per day) for patients failing both treatments [74,76].

Of note, a prognostic value of response to MTX was observed in patients characterized by the STAT3 Y640F mutation [66]. Thus, MTX represents the current recommended option for neutropenic patients with this specific genetic lesion. A randomized prospective trial (\#NCT01976182) comparing first-line MTX versus CTX is investigating the best therapeutic choice, also aiming at identifying other potential markers of response [22].

A minimum of 4-6 months of treatment is required before assessing response. Both MTX and CyA can be maintained indefinitely, according to their tolerance. In contrast, CTX should not be used for periods longer than 6-12 months because of its mutagenic potential [75]. Regardless of the treatment status, patients should be routinely monitored for symptoms and disease progression. Specific recommendations during the follow up include regular liver tests and chest radiographs for long-term use of MTX, while renal function and blood pressure need to be evaluated during CyA treatment [22,66,76-78]. 


\subsection{Splenectomy and Supportive Therapy}

Even though splenomegaly is described in $20-50 \%$ of patients, a relevant role of spleenmediated destruction of neutrophils is not supported by histological findings $[30,79,80]$. Moreover, long-lasting responses were rarely observed in splenectomized patients, aside from a transient improvement of neutropenia. Thus, splenectomy should be limited to patients with splenomegaly-related symptoms [81].

Treatment with granulocyte-colony stimulating factor (G-CSF) may be effective in rapidly increasing the ANC. However, both splenomegaly and joint pains may get worse with prolonged G-CSF administration [13].

\subsection{Salvage Therapies}

The optimal strategy for $R / R$ patients is difficult to assess, since prospective trials based on large cohorts of patients are limited. Purine analogs, such as fludarabine, cladribine, pentostatin and bendamustine were used in small series of $R / R$ patients (less than 50 cases), with promising ORR (70-80\%) [13].

In addition, immunotherapy with the monoclonal antibodies alemtuzumab (antiCD52) and rituximab (anti-CD20) was considered in refractory LGLL cases. In detail, alemtuzumab showed an ORR of $74 \%$ and $47 \%$ CR rates [82]. This drug, however, should be restricted to selected cases, due to its high toxicity. Although the use of rituximab in LGLL might appear counterintuitive, it was reported to be effective in impairing leukemic cell survival and in the recovery of LGLL clinical manifestation, including neutropenia, in a patient with concomitant RA [83].

Polychemotherapy combination regimens, on the contrary, are reported to be ineffective and toxic in chronic LGL proliferations [13].

\subsection{Emerging Therapeutic Options for LGLL Patients}

According to the complex and heterogeneous pathogenesis of LGLL, several efforts were made to develop novel therapeutic approaches. In this regard, the inhibition of the JAK/STAT3 axis might represent a potential and attractive therapeutic strategy, especially for patients presenting with neutropenia. Tofacitinib citrate, a JAK3-specific inhibitor, showed its efficacy in 9 T-LGLL/RA patients, refractory to conventional therapy. A hematological response was observed in 6/9 (67\%) cases, with 5 out of $7(71 \%)$ neutropenic patients showing an increase of ANC [84]. Even with limitations due to the small cohort, tofacitinib revealed an increased efficacy in STAT3-mutated cases, as compared to those with wild-type STAT3 [84].

Focusing on the pathogenetic mechanisms of neutropenia, specific alterations (e.g., $\mathrm{miR}-146 \mathrm{~b}$ defective expression) were demonstrated to be consequent to an increased level of methylation of gene promoters [12]. Accordingly, the clinical efficacy of epigenetic modifiers should be prospectively addressed; to date, evidence on $5^{\prime}$-Aza-2'-deoxycytidine (a demethylating agent) $[12,16]$ or belinostat (a histone deacetylase inhibitor) have been reported, supporting this potential therapeutic approach [85].

Another class of compounds to be considered in the therapeutic scenario of LGLL patients are proteasome inhibitors (PI), e.g., bortezomib and ixazomib, which are both approved for the treatment of multiple myeloma $(\mathrm{MM})$ and various leukemias/lymphomas. These molecules are able to induce in vitro leukemic LGL apoptosis with different mechanisms, including the increase of intracellular levels of pro-apoptotic protein (e.g., Bid), commonly degraded via ubiquitination, and the inhibition of the nuclear factor k-B (NF-kB) signaling pathway $[86,87]$. In addition, a reduction of leukemic LGL in patients with concurrent LGLL and MM, treated with bortezomib for the plasma cell neoplasia, is documented [88]. Although this evidence is encouraging, it should be considered the potential toxicity of these therapeutic options. Thus, prospective trials are needed to investigate the efficacy and safety of these drugs in large cohorts of patients.

Among the emerging therapeutic option, there is also a multi cytokine inhibitor BNZ-1, which selectively inhibits IL-2, IL-15 and, to a lesser degree, IL-9 signaling. Previous reports 
have shown the effect of pro-inflammatory cytokines, including IL-15, to promote STAT3 activation [41]. A phase I/II trial (\#NCT03239392) is ongoing to test this molecule in LGLL patients, with promising expectations [89].

\section{Conclusions and Future Directions}

Chronic isolated neutropenia is the clinical hallmark of LGLL patients and the most common indication for treatment. In this paper, we described a heterogeneous picture of the disease, suggesting that different subsets of patients might be characterized by discrete features and abnormalities accounting for neutropenia development. According to current evidence $[7,41,68]$, immunophenotypic and STAT3 mutational analyses are useful in the early identification of neutropenic LGLL patients. Moreover, this longitudinal relationship might be helpful to manage patients during the natural history of the disease.

By contrast, treatment still remains a challenging task, mainly based on empirical approaches. A targeted treatment and specific guidelines are not available, with IST being the conventional, but poorly effective, therapeutic strategy. Moreover, data on other therapeutic options are erratic and limited to small series, emphasizing the lack of effective therapies, which still represents an unmet clinical need.

We previously focused on miR-146b-FasL axis, according to the recent description of its key role in neutropenia development in T-LGLL patients [12]. Even if it could be tempting to identify FasL as a new therapeutic target for neutropenic LGLL patients, the neutralization of this pivotal signaling molecule may lead to severe side effects, that is a strong limitation. Differently, miR-146b might represent an ideal and promising candidate for the development of an innovative targeted therapy, being its defective expression a molecular signature of neutropenic patients. New advances regarding miRNA-based therapies was achieved, either based on miRNA mimics to restore lost endogenous miRNA or antagomirs to counteract the overexpression of oncogenic miRNA in cancer cells $[90,91]$. One of the main challenges of a miRNA-based therapy relies on the effective and selective delivery of miRNA molecules to target cells. MiR-146b restoration in leukemic T-LGL might be attained through engineered delivery systems, such as antibody-conjugated nanocarriers. Additional studies are ongoing to assess the potential role of miR-146b restoration as a novel therapeutic option for neutropenic LGLL patients.

Author Contributions: G.C. wrote the manuscript; G.C., A.T., G.B., C.V., V.R.G., G.S. and R.Z. checked the data contained in the manuscript; G.S. and R.Z. reviewed and edited the manuscript. All authors have read and agreed to the published version of the manuscript.

Funding: The research of Prof. Gianpietro Semenzato is funded by the Italian Association of Cancer Research (AIRC), grant number: IG-20216.

Institutional Review Board Statement: Not applicable.

Informed Consent Statement: Not applicable.

Data Availability Statement: Not applicable.

Conflicts of Interest: The authors declare no conflict of interest.

\section{References}

1. Loughran, T.P., Jr. Clonal Diseases of Large Granular Lymphocytes. Blood 1993, 82, 1-14. [CrossRef]

2. Swerdlow, S.H.; Campo, E.; Pileri, S.A.; Harris, N.L.; Stein, H.; Siebert, R.; Advani, R.; Ghielmini, M.; Salles, G.A.; Zelenetz, A.D.; et al. The 2016 Revision of the World Health Organization Classification of Lymphoid Neoplasms. Blood 2016, 127, 2375-2390. [CrossRef]

3. Shah, M.V.; Hook, C.C.; Call, T.G.; Go, R.S. A Population-Based Study of Large Granular Lymphocyte Leukemia. Blood Cancer J. 2016, 6, e455. [CrossRef]

4. Dinmohamed, A.G.; Brink, M.; Visser, O.; Jongen-Lavrencic, M. Population-Based Analyses among 184 Patients Diagnosed with Large Granular Lymphocyte Leukemia in the Netherlands between 2001 and 2013. Leukemia 2016, 30, 1449-1451. [CrossRef]

5. Matutes, E. The 2017 WHO Update on Mature T- and Natural Killer (NK) Cell Neoplasms. Int. J. Lab. Hematol. 2018, 40 (Suppl. 1), 97-103. [CrossRef] 
6. Jerez, A.; Clemente, M.J.; Makishima, H.; Koskela, H.; Leblanc, F.; Peng, N.K.; Olson, T.; Przychodzen, B.; Afable, M.; GomezSegui, I.; et al. STAT3 Mutations Unify the Pathogenesis of Chronic Lymphoproliferative Disorders of NK Cells and T-Cell Large Granular Lymphocyte Leukemia. Blood 2012, 120, 3048-3057. [CrossRef]

7. Barilà, G.; Calabretto, G.; Teramo, A.; Vicenzetto, C.; Gasparini, V.R.; Semenzato, G.; Zambello, R. T Cell Large Granular Lymphocyte Leukemia and Chronic NK Lymphocytosis. Best Pract. Res. Clin. Haematol. 2019, 32, 207-216. [CrossRef]

8. Bareau, B.; Rey, J.; Hamidou, M.; Donadieu, J.; Morcet, J.; Reman, O.; Schleinitz, N.; Tournilhac, O.; Roussel, M.; Fest, T.; et al. Analysis of a French Cohort of Patients with Large Granular Lymphocyte Leukemia: A Report on 229 Cases. Haematologica 2010, 95, 1534-1541. [CrossRef]

9. Sanikommu, S.R.; Clemente, M.J.; Chomczynski, P.; Afable, M.G., 2nd; Jerez, A.; Thota, S.; Patel, B.; Hirsch, C.; Nazha, A.; Desamito, J.; et al. Clinical Features and Treatment Outcomes in Large Granular Lymphocytic Leukemia (LGLL). Leuk. Lymphoma 2018, 59, 416-422. [CrossRef]

10. Barilà, G.; Teramo, A.; Calabretto, G.; Vicenzetto, C.; Gasparini, V.R.; Pavan, L.; Leoncin, M.; Vedovato, S.; Frigo, A.C.; Facco, M.; et al. Stat3 Mutations Impact on Overall Survival in Large Granular Lymphocyte Leukemia: A Single-Center Experience of 205 Patients. Leukemia 2020, 34, 1116-1124. [CrossRef]

11. Dong, N.; Tokumori, F.C.; Isenalumhe, L.; Zhang, Y.; Tandon, A.; Knepper, T.C.; Mo, Q.; Shao, H.; Zhang, L.; Sokol, L. Large Granular Lymphocytic Leukemia-A Retrospective Study of 319 Cases. Am. J. Hematol. 2021, 96, 772-780. [CrossRef] [PubMed]

12. Mariotti, B.; Calabretto, G.; Rossato, M.; Teramo, A.; Castellucci, M.; Barilà, G.; Leoncin, M.; Vicenzetto, C.; Facco, M.; Semenzato, G.; et al. Identification of a miR-146b-Fas Ligand Axis in the Development of Neutropenia in T Large Granular Lymphocyte Leukemia. Haematologica 2020, 105, 1351-1360. [CrossRef]

13. Lamy, T.; Moignet, A.; Loughran, T.P. LGL Leukemia: From Pathogenesis to Treatment. Blood 2017, 129, 1082-1094. [CrossRef]

14. Zambello, R.; Berno, T.; Cannas, G.; Baesso, I.; Binotto, G.; Bonoldi, E.; Bevilacqua, P.; Miorin, M.; Facco, M.; Trentin, L.; et al. Phenotypic and Functional Analyses of Dendritic Cells in Patients with Lymphoproliferative Disease of Granular Lymphocytes (LDGL). Blood 2005, 106, 3926-3931. [CrossRef]

15. Yoon, H.J.; Sugamura, K.; Loughran, T.P., Jr. Activation of Leukemic Large Granular Lymphocytes by Interleukin-2 via the p75 Interleukin-2 Receptor. Leukemia 1990, 4, 848-850.

16. Teramo, A.; Gattazzo, C.; Passeri, F.; Lico, A.; Tasca, G.; Cabrelle, A.; Martini, V.; Frezzato, F.; Trimarco, V.; Ave, E.; et al. Intrinsic and Extrinsic Mechanisms Contribute to Maintain the JAK/STAT Pathway Aberrantly Activated in T-Type Large Granular Lymphocyte Leukemia. Blood 2013, 121, 3843-3854. [CrossRef]

17. Zambello, R.; Facco, M.; Trentin, L.; Sancetta, R.; Tassinari, C.; Perin, A.; Milani, A.; Pizzolo, G.; Rodeghiero, F.; Agostini, C.; et al. Interleukin-15 Triggers the Proliferation and Cytotoxicity of Granular Lymphocytes in Patients with Lymphoproliferative Disease of Granular Lymphocytes. Blood 1997, 89, 201-211. [CrossRef]

18. Mishra, A.; Liu, S.; Sams, G.H.; Curphey, D.P.; Santhanam, R.; Rush, L.J.; Schaefer, D.; Falkenberg, L.G.; Sullivan, L.; Jaroncyk, L.; et al. Aberrant Overexpression of IL-15 Initiates Large Granular Lymphocyte Leukemia through Chromosomal Instability and DNA Hypermethylation. Cancer Cell 2012, 22, 645-655. [CrossRef]

19. Kothapalli, R.; Nyland, S.B.; Kusmartseva, I.; Bailey, R.D.; McKeown, T.M.; Loughran, T.P., Jr. Constitutive Production of Proinflammatory Cytokines RANTES, MIP-1beta and IL-18 Characterizes LGL Leukemia. Int. J. Oncol. 2005, 26, 529-535.

20. Yang, J.; Liu, X.; Nyland, S.B.; Zhang, R.; Ryland, L.K.; Broeg, K.; Baab, K.T.; Jarbadan, N.R.; Irby, R.; Loughran, T.P., Jr. PlateletDerived Growth Factor Mediates Survival of Leukemic Large Granular Lymphocytes via an Autocrine Regulatory Pathway. Blood 2010, 115, 51-60. [CrossRef]

21. Sun, H.; Wei, S.; Yang, L. Dysfunction of Immune System in the Development of Large Granular Lymphocyte Leukemia. Hematology 2019, 24, 139-147. [CrossRef]

22. Moignet, A.; Lamy, T. Latest Advances in the Diagnosis and Treatment of Large Granular Lymphocytic Leukemia. Am. Soc. Clin. Oncol. Educ. Book 2018, 38, 616-625. [CrossRef]

23. Nauseef, W.M. Neutrophils, from Cradle to Grave and beyond. Immunol. Rev. 2016, 273, 5-10. [CrossRef] [PubMed]

24. Yvan-Charvet, L.; Ng, L.G. Granulopoiesis and Neutrophil Homeostasis: A Metabolic, Daily Balancing Act. Trends Immunol. 2019, 40, 598-612. [CrossRef] [PubMed]

25. McCracken, J.M.; Allen, L.-A.H. Regulation of Human Neutrophil Apoptosis and Lifespan in Health and Disease. J. Cell Death 2014, 7, 15-23. [CrossRef] [PubMed]

26. Hidalgo, A.; Chilvers, E.R.; Summers, C.; Koenderman, L. The Neutrophil Life Cycle. Trends Immunol. 2019, 40, 584-597. [CrossRef]

27. Boxer, L.A. How to Approach Neutropenia. Hematol. Am. Soc. Hematol. Educ. Program 2012, 2012, 174-182. [CrossRef] [PubMed]

28. Autrel-Moignet, A.; Lamy, T. Autoimmune Neutropenia. Presse Med. 2014, 43, e105-e118. [CrossRef] [PubMed]

29. Gazitt, T.; Loughran, T.P., Jr. Chronic Neutropenia in LGL Leukemia and Rheumatoid Arthritis. Hematol. Am. Soc. Hematol. Educ. Program 2017, 2017, 181-186. [CrossRef]

30. Burks, E.J.; Loughran, T.P., Jr. Pathogenesis of Neutropenia in Large Granular Lymphocyte Leukemia and Felty Syndrome. Blood Rev. 2006, 20, 245-266. [CrossRef]

31. Pontikoglou, C.; Kalpadakis, C.; Papadaki, H.A. Pathophysiologic Mechanisms and Management of Neutropenia Associated with Large Granular Lymphocytic Leukemia. Expert Rev. Hematol. 2011, 4, 317-328. [CrossRef] 
32. Loughran, T.P., Jr.; Kadin, M.E.; Starkebaum, G.; Abkowitz, J.L.; Clark, E.A.; Disteche, C.; Lum, L.G.; Slichter, S.J. Leukemia of Large Granular Lymphocytes: Association with Clonal Chromosomal Abnormalities and Autoimmune Neutropenia, Thrombocytopenia, and Hemolytic Anemia. Ann. Intern. Med. 1985, 102, 169-175. [CrossRef] [PubMed]

33. Bassan, R.; Pronesti, M.; Buzzetti, M.; Allavena, P.; Rambaldi, A.; Mantovani, A.; Barbui, T. Autoimmunity and B-Cell Dysfunction in Chronic Proliferative Disorders of Large Granular Lymphocytes/natural Killer Cells. Cancer 1989, 63, 90-95. [CrossRef]

34. Sivakumaran, M.; Richards, S. Immunological Abnormalities of Chronic Large Granular Lymphocytosis. Clin. Lab. Haematol. 1997, 19, 57-60. [CrossRef] [PubMed]

35. Gentile, T.C.; Wener, M.H.; Starkebaum, G.; Loughran, T.P., Jr. Humoral Immune Abnormalities in T-Cell Large Granular Lymphocyte Leukemia. Leuk. Lymphoma 1996, 23, 365-370. [CrossRef] [PubMed]

36. Rustagi, P.K.; Han, T.; Ziolkowski, L.; Farolino, D.L.; Currie, M.S.; Logue, G.L. Granulocyte Antibodies in Leukaemic Chronic Lymphoproliferative Disorders. Br. J. Haematol. 1987, 66, 461-465. [CrossRef] [PubMed]

37. Starkebaum, G.; Martin, P.J.; Singer, J.W.; Lum, L.G.; Price, T.H.; Kadin, M.E.; Raskind, W.H.; Fialkow, P.J. Chronic Lymphocytosis with Neutropenia: Evidence for a Novel, Abnormal T-Cell Population Associated with Antibody-Mediated Neutrophil Destruction. Clin. Immunol. Immunopathol. 1983, 27, 110-123. [CrossRef]

38. Van der Veen, J.P.; Goldschmeding, R.; Miedema, F.; Smit, J.W.; Melief, C.J.; von dem Borne, A.E. K-Cell Lymphocytosis/neutropenia Syndrome: The Neutropenia Is Not Caused by Autoimmunity. Br. J. Haematol. 1986, 64, 777-787. [CrossRef] [PubMed]

39. Tanaka, M.; Suda, T.; Haze, K.; Nakamura, N.; Sato, K.; Kimura, F.; Motoyoshi, K.; Mizuki, M.; Tagawa, S.; Ohga, S.; et al. Fas Ligand in Human Serum. Nat. Med. 1996, 2, 317-322. [CrossRef] [PubMed]

40. Liu, J.H.; Wei, S.; Lamy, T.; Epling-Burnette, P.K.; Starkebaum, G.; Djeu, J.Y.; Loughran, T.P. Chronic Neutropenia Mediated by Fas Ligand. Blood 2000, 95, 3219-3222. [CrossRef]

41. Teramo, A.; Barilà, G.; Calabretto, G.; Ercolin, C.; Lamy, T.; Moignet, A.; Roussel, M.; Pastoret, C.; Leoncin, M.; Gattazzo, C.; et al. STAT3 Mutation Impacts Biological and Clinical Features of T-LGL Leukemia. Oncotarget 2017, 8, 61876-61889. [CrossRef] [PubMed]

42. Perzova, R.; Loughran, T.P. Constitutive Expression of Fas Ligand in Large Granular Lymphocyte Leukaemia. Br. J. Haematol. 1997, 97, 123-126. [CrossRef]

43. Lamy, T.; Liu, J.H.; Landowski, T.H.; Dalton, W.S.; Loughran, T.P. Dysregulation of CD95/CD95 Ligand-Apoptotic Pathway in CD3 Large Granular Lymphocyte Leukemia. Blood 1998, 92, 4771-4777. [CrossRef]

44. Saitoh, T.; Karasawa, M.; Sakuraya, M.; Norio, N.; Junko, T.; Shirakawa, K.; Matsushima, T.; Tsukamoto, N.; Nojima, Y.; Murakami, H. Improvement of Extrathymic T Cell Type of Large Granular Lymphocyte (LGL) Leukemia by Cyclosporin A: The Serum Level of Fas Ligand Is a Marker of LGL Leukemia Activity. Eur. J. Haematol. 2000, 65, 272-275. [CrossRef]

45. Liles, W.C.; Kiener, P.A.; Ledbetter, J.A.; Aruffo, A.; Klebanoff, S.J. Differential Expression of Fas (CD95) and Fas Ligand on Normal Human Phagocytes: Implications for the Regulation of Apoptosis in Neutrophils. J. Exp. Med. 1996, 184, 429-440. [CrossRef]

46. Maciejewski, J.; Selleri, C.; Anderson, S.; Young, N.S. Fas Antigen Expression on CD34+ Human Marrow Cells Is Induced by Interferon Gamma and Tumor Necrosis Factor Alpha and Potentiates Cytokine-Mediated Hematopoietic Suppression in Vitro. Blood 1995, 85, 3183-3190. [CrossRef]

47. Maciejewski, J.P.; Selleri, C.; Sato, T.; Anderson, S.; Young, N.S. Increased Expression of Fas Antigen on Bone Marrow CD34+ Cells of Patients with Aplastic Anaemia. Br. J. Haematol. 1995, 91, 245-252. [CrossRef]

48. Hooks, J.J.; Haynes, B.F.; Detrick-Hooks, B.; Diehl, L.F.; Gerrard, T.L.; Fauci, A.S. Gamma (immune) Interferon Production by Leukocytes from a Patient with a TG Cell Proliferative Disease. Blood 1982, 59, 198-201. [CrossRef]

49. Bank, I.; Cohen, L.; Kneller, A.; De Rosbo, N.K.; Book, M.; Ben-Nun, A. Aberrant T-Cell Receptor Signalling of Interferon-Gammaand Tumour Necrosis Factor-Alpha-Producing Cytotoxic CD8+ Vdelta1/Vbeta16 T Cells in a Patient with Chronic Neutropenia. Scand. J. Immunol. 2003, 58, 89-98. [CrossRef] [PubMed]

50. Zambello, R.; Semenzato, G. Large Granular Lymphocyte Disorders: New Etiopathogenetic Clues as a Rationale for Innovative Therapeutic Approaches. Haematologica 2009, 94, 1341-1345. [CrossRef] [PubMed]

51. Picker, L.J.; Furst, A.; Robinson, S.H.; Kadin, M.E. Immunoarchitecture of the Bone Marrow in Neutropenia: Increased HNK-1 + Cells Define a Subset of Neutropenic Patients. Am. J. Hematol. 1987, 25, 29-41. [CrossRef]

52. Evans, H.L.; Burks, E.; Viswanatha, D.; Larson, R.S. Utility of Immunohistochemistry in Bone Marrow Evaluation of T-Lineage Large Granular Lymphocyte Leukemia. Hum. Pathol. 2000, 31, 1266-1273. [CrossRef]

53. Osuji, N.; Beiske, K.; Randen, U.; Matutes, E.; Tjonnfjord, G.; Catovsky, D.; Wotherspoon, A. Characteristic Appearances of the Bone Marrow in T-Cell Large Granular Lymphocyte Leukaemia. Histopathology 2007, 50, 547-554. [CrossRef] [PubMed]

54. Morice, W.G.; Kurtin, P.J.; Tefferi, A.; Hanson, C.A. Distinct Bone Marrow Findings in T-Cell Granular Lymphocytic Leukemia Revealed by Paraffin Section Immunoperoxidase Stains for CD8, TIA-1, and Granzyme B. Blood 2002, 99, 268-274. [CrossRef] [PubMed]

55. Coakley, G.; Iqbal, M.; Brooks, D.; Panayi, G.S.; Lanchbury, J.S. CD8+, CD57+ T Cells from Healthy Elderly Subjects Suppress Neutrophil Development in Vitro: Implications for the Neutropenia of Felty's and Large Granular Lymphocyte Syndromes. Arthritis Rheum. 2000, 43, 834-843. [CrossRef] 
56. Mailloux, A.W.; Zhang, L.; Moscinski, L.; Bennett, J.M.; Yang, L.; Yoder, S.J.; Bloom, G.; Wei, C.; Wei, S.; Sokol, L.; et al. Fibrosis and Subsequent Cytopenias Are Associated with Basic Fibroblast Growth Factor-Deficient Pluripotent Mesenchymal Stromal Cells in Large Granular Lymphocyte Leukemia. J. Immunol. 2013, 191, 3578-3593. [CrossRef] [PubMed]

57. Zambello, R.; Semenzato, G. Natural Killer Receptors in Patients with Lymphoproliferative Diseases of Granular Lymphocytes. Semin. Hematol. 2003, 40, 201-212. [CrossRef]

58. Zambello, R.; Falco, M.; Della Chiesa, M.; Trentin, L.; Carollo, D.; Castriconi, R.; Cannas, G.; Carlomagno, S.; Cabrelle, A.; Lamy, T.; et al. Expression and Function of KIR and Natural Cytotoxicity Receptors in NK-Type Lymphoproliferative Diseases of Granular Lymphocytes. Blood 2003, 102, 1797-1805. [CrossRef]

59. Scquizzato, E.; Teramo, A.; Miorin, M.; Facco, M.; Piazza, F.; Noventa, F.; Trentin, L.; Agostini, C.; Zambello, R.; Semenzato, G. Genotypic Evaluation of Killer Immunoglobulin-like Receptors in NK-Type Lymphoproliferative Disease of Granular Lymphocytes. Leukemia 2007, 21, 1060-1069. [CrossRef]

60. Howe, E.C.; Wlodarski, M.; Ball, E.J.; Rybicki, L.; Maciejewski, J.P. Killer Immunoglobulin-like Receptor Genotype in ImmuneMediated Bone Marrow Failure Syndromes. Exp. Hematol. 2005, 33, 1357-1362. [CrossRef]

61. Handgretinger, R.; Geiselhart, A.; Moris, A.; Grau, R.; Teuffel, O.; Bethge, W.; Kanz, L.; Fisch, P. Pure Red-Cell Aplasia Associated with Clonal Expansion of Granular Lymphocytes Expressing Killer-Cell Inhibitory Receptors. N. Engl. J. Med. 1999, 340, $278-284$. [CrossRef]

62. Nearman, Z.P.; Wlodarski, M.; Jankowska, A.M.; Howe, E.; Narvaez, Y.; Ball, E.; Maciejewski, J.P. Immunogenetic Factors Determining the Evolution of T-Cell Large Granular Lymphocyte Leukaemia and Associated Cytopenias. Br. J. Haematol. 2007, 136, 237-248. [CrossRef]

63. Wlodarski, M.W.; O’Keefe, C.; Howe, E.C.; Risitano, A.M.; Rodriguez, A.; Warshawsky, I.; Loughran, T.P., Jr.; Maciejewski, J.P. Pathologic Clonal Cytotoxic T-Cell Responses: Nonrandom Nature of the T-Cell-Receptor Restriction in Large Granular Lymphocyte Leukemia. Blood 2005, 106, 2769-2780. [CrossRef]

64. Zhang, D.; Loughran, T.P., Jr. Large Granular Lymphocytic Leukemia: Molecular Pathogenesis, Clinical Manifestations, and Treatment. Hematology Am. Soc. Hematol. Educ. Program 2012, 2012, 652-659. [CrossRef] [PubMed]

65. Teramo, A.; Barilà, G.; Calabretto, G.; Vicenzetto, C.; Gasparini, V.R.; Semenzato, G.; Zambello, R. Insights Into Genetic Landscape of Large Granular Lymphocyte Leukemia. Front. Oncol. 2020, 10, 152. [CrossRef] [PubMed]

66. Loughran, T.P., Jr.; Zickl, L.; Olson, T.L.; Wang, V.; Zhang, D.; Rajala, H.L.M.; Hasanali, Z.; Bennett, J.M.; Lazarus, H.M.; Litzow, M.R.; et al. Immunosuppressive Therapy of LGL Leukemia: Prospective Multicenter Phase II Study by the Eastern Cooperative Oncology Group (E5998). Leukemia 2015, 29, 886-894. [CrossRef] [PubMed]

67. Gabrielli, S.; Ortolani, C.; Del Zotto, G.; Luchetti, F.; Canonico, B.; Buccella, F.; Artico, M.; Papa, S.; Zamai, L. The Memories of NK Cells: Innate-Adaptive Immune Intrinsic Crosstalk. J. Immunol. Res. 2016, 2016, 1376595. [CrossRef]

68. Barilà, G.; Teramo, A.; Calabretto, G.; Ercolin, C.; Boscaro, E.; Trimarco, V.; Carraro, S.; Leoncin, M.; Vicenzetto, C.; Cabrelle, A.; et al. Dominant Cytotoxic NK Cell Subset within CLPD-NK Patients Identifies a More Aggressive NK Cell Proliferation. Blood Cancer J. 2018, 8, 51. [CrossRef] [PubMed]

69. Mohan, S.R.; Maciejewski, J.P. Diagnosis and Therapy of Neutropenia in Large Granular Lymphocyte Leukemia. Curr. Opin. Hematol. 2009, 16, 27-34. [CrossRef]

70. Savola, P.; Brück, O.; Olson, T.; Kelkka, T.; Kauppi, M.J.; Kovanen, P.E.; Kytölä, S.; Sokka-Isler, T.; Loughran, T.P.; Leirisalo-Repo, M.; et al. Somatic STAT3 Mutations in Felty Syndrome: An Implication for a Common Pathogenesis with Large Granular Lymphocyte Leukemia. Haematologica 2018, 103, 304-312. [CrossRef]

71. Komrokji, R.S.; Ali, N.A.; Sallman, D.; Padron, E.; Lancet, J.; Sokol, L.; Varnadoe, C.; Burnette, P.K.; List, A. Characterization of Myelodysplastic Syndromes (MDS) with T-Cell Large Granular Lymphocyte Proliferations (LGL). Leukemia 2020, 34, 3097-3099. [CrossRef]

72. Durrani, J.; Awada, H.; Kishtagari, A.; Visconte, V.; Kerr, C.; Adema, V.; Nagata, Y.; Kuzmanovic, T.; Hong, S.; Patel, B.; et al. Large Granular Lymphocytic Leukemia Coexists with Myeloid Clones and Myelodysplastic Syndrome. Leukemia 2020, 34, 957-962. [CrossRef]

73. Jerez, A.; Clemente, M.J.; Makishima, H.; Rajala, H.; Gómez-Seguí, I.; Olson, T.; McGraw, K.; Przychodzen, B.; Kulasekararaj, A.; Afable, M.; et al. STAT3 Mutations Indicate the Presence of Subclinical T-Cell Clones in a Subset of Aplastic Anemia and Myelodysplastic Syndrome Patients. Blood 2013, 122, 2453-2459. [CrossRef] [PubMed]

74. Cheon, H.; Dziewulska, K.H.; Moosic, K.B.; Olson, K.C.; Gru, A.A.; Feith, D.J.; Loughran, T.P., Jr. Advances in the Diagnosis and Treatment of Large Granular Lymphocytic Leukemia. Curr. Hematol. Malig. Rep. 2020, 15, 103-112. [CrossRef] [PubMed]

75. Wolfrom, C.M.; Lévy, V.; Deschatrette, J. Neutropenia Dynamics in a Case of T-LGL Lymphoproliferation Illustrate Rapid Turnover of Granulocyte Progenitors. Cell Prolif. 2010, 43, 326-332. [CrossRef] [PubMed]

76. Lamy, T.; Loughran, T.P. How I Treat LGL Leukemia. Blood 2011, 117, 2764-2774. [CrossRef]

77. Lamy, T.; Pastoret, C.; Houot, R.; Ysebaert, L.; Hunault, M.; Damaj, G.; Banos, A.; Tournilhac, O.; Choufi, B.; Marolleau, J.-P.; et al. Prospective, Multicentric Phase II Randomized Trial Comparing the Efficacy of Methotrexate or Cyclophosphamide in Large Granular Lymphocytic Leukemia: A French National Study. Report on the Interim Analysis. Blood 2019, 134, 1545. [CrossRef]

78. Moignet, A.; Hasanali, Z.; Zambello, R.; Pavan, L.; Bareau, B.; Tournilhac, O.; Roussel, M.; Fest, T.; Awwad, A.; Baab, K.; et al. Cyclophosphamide as a First-Line Therapy in LGL Leukemia. Leukemia 2014, 28, 1134-1136. [CrossRef] 
79. Osuji, N.; Matutes, E.; Catovsky, D.; Lampert, I.; Wotherspoon, A. Histopathology of the Spleen in T-Cell Large Granular Lymphocyte Leukemia and T-Cell Prolymphocytic Leukemia: A Comparative Review. Am. J. Surg. Pathol. 2005, $29,935-941$. [CrossRef]

80. Subbiah, V.; Viny, A.D.; Rosenblatt, S.; Pohlman, B.; Lichtin, A.; Maciejewski, J.P. Outcomes of Splenectomy in T-Cell Large Granular Lymphocyte Leukemia with Splenomegaly and Cytopenia. Exp. Hematol. 2008, 36, 1078-1083. [CrossRef]

81. Loughran, T.P., Jr.; Starkebaum, G.; Clark, E.; Wallace, P.; Kadin, M.E. Evaluation of Splenectomy in Large Granular Lymphocyte Leukaemia. Br. J. Haematol. 1987, 67, 135-140. [CrossRef]

82. Dumitriu, B.; Ito, S.; Feng, X.; Stephens, N.; Yunce, M.; Kajigaya, S.; Melenhorst, J.J.; Rios, O.; Scheinberg, P.; Chinian, F.; et al. Alemtuzumab in T-Cell Large Granular Lymphocytic Leukaemia: Interim Results from a Single-Arm, Open-Label, Phase 2 Study. Lancet Haematol 2016, 3, e22-e29. [CrossRef]

83. Cornec, D.; Devauchelle-Pensec, V.; Jousse-Joulin, S.; Marhadour, T.; Ugo, V.; Berthou, C.; Douet-Guilbert, N.; Saraux, A. LongTerm Remission of T-Cell Large Granular Lymphocyte Leukemia Associated with Rheumatoid Arthritis after Rituximab Therapy. Blood 2013, 122, 1583-1586. [CrossRef]

84. Bilori, B.; Thota, S.; Clemente, M.J.; Patel, B.; Jerez, A.; Afable, M., II; Maciejewski, J.P. Tofacitinib as a Novel Salvage Therapy for Refractory T-Cell Large Granular Lymphocytic Leukemia. Leukemia 2015, 29, 2427-2429. [CrossRef]

85. Poh, C.; Arora, M.; Ghuman, S.; Tuscano, J. Belinostat in Relapsed/Refractory T-Cell Large Granular Lymphocyte Leukemia. Acta Haematol. 2021, 144, 95-99. [CrossRef]

86. Hodge, D.L.; Yang, J.; Buschman, M.D.; Schaughency, P.M.; Dang, H.; Bere, W.; Yang, Y.; Savan, R.; Subleski, J.J.; Yin, X.-M.; et al. Interleukin-15 Enhances Proteasomal Degradation of Bid in Normal Lymphocytes: Implications for Large Granular Lymphocyte Leukemias. Cancer Res. 2009, 69, 3986-3994. [CrossRef] [PubMed]

87. Yang, J.; LeBlanc, F.R.; Dighe, S.A.; Hamele, C.E.; Olson, T.L.; Feith, D.J.; Loughran, T.P., Jr. TRAIL Mediates and Sustains Constitutive NF-kB Activation in LGL Leukemia. Blood 2018, 131, 2803-2815. [CrossRef]

88. Pelliccia, S.; Di Napoli, A.; Naso, V.; Alma, E.; Rebecchini, C.; Cox, M.C. Very Long-Lasting Remission of Refractory T-Large Granular Lymphocytes Leukemia and Myeloma by Lenalidomide Treatment. Eur. J. Haematol. 2013, 91, 183-186. [CrossRef] [PubMed]

89. Frohna, P.; Tagaya, Y.; Ratnayake, A.; Doerr, N.; Basheer, A.; Al-Mawsawi, L.; Kim, W.J.; Zapata, J.; Wu, X.; Azimi, N. Results from a First-in-Human Study with Bnz-1: A Novel Peptide Inhibitor of IL-2, IL-9 and IL-15 for the Treatment of T-Cell Malignancies That Safely and Selectively Decreases Regulatory T-Cells, Natural Killer Cells, and CD8 Central Memory T-Cells. Blood 2017, 130, 695. [CrossRef]

90. Bajan, S.; Hutvagner, G. RNA-Based Therapeutics: From Antisense Oligonucleotides to miRNAs. Cells 2020, 9, 137. [CrossRef] [PubMed]

91. Zhou, L.-Y.; Qin, Z.; Zhu, Y.-H.; He, Z.-Y.; Xu, T. Current RNA-Based Therapeutics in Clinical Trials. Curr. Gene Ther. 2019, 19, 172-196. [CrossRef] [PubMed] 